Article

\title{
Involvement of MAFB and MAFF in Retinoid-Mediated Suppression of Hepatocellular Carcinoma Invasion
}

\author{
Hiroyuki Tsuchiya ${ }^{1, *(1)}$ and Seiya Oura ${ }^{2}$ \\ 1 Graduate School of Medicine, Tottori University, Tottori 680-8550, Japan \\ 2 Graduate School of Pharmaceutical Sciences, Osaka University, Osaka 565-0871, Japan; \\ oura@biken.osaka-u.ac.jp \\ * Correspondence: tsuchiya@med.tottori-u.ac.jp; Tel.: +81-859-38-6435
}

Received: 19 March 2018; Accepted: 10 May 2018; Published: 13 May 2018

\begin{abstract}
Retinoids exert antitumor effects through the retinoic acid receptor $\alpha$ (RAR $\alpha)$. In the present study, we sought to identify the factors involved in the RAR $\alpha$-mediated transcriptional regulation of the tumor suppressor gene and the tissue factor pathway inhibitor 2 (TFPI2) in hepatocellular carcinoma (HCC). All-trans-retinoic acid (ATRA) was used in the in vitro experiments. Cell invasiveness was measured using trans-well invasion assay. ATRA significantly increased TFPI2 expression through RAR $\alpha$ in a human HCC cell line known as HuH7. TFPI2 was vital in the ATRA-mediated suppression of HuH7 cell invasion. The musculo-aponeurotic fibrosarcoma oncogene homolog B (MAFB) significantly enhanced the activation of the TFPI2 promoter via RAR $\alpha$ while MAFF inhibited it. The knockdown of RAR $\alpha$ or MAFB counteracted the ATRA-mediated suppression of HuH7 cell invasion while the knockdown of MAFF inhibited the invasion. TFPI2 expression in HCC tissues was significantly downregulated possibly due to the decreased expression of RAR $\beta$ and MAFB. Patients with HCC expressing low MAFB and high MAFF levels showed the shortest disease-free survival time. These results suggest that MAFB and MAFF play critical roles in the antitumor effects of retinoids by regulating the expression of retinoid target genes such as TFPI2 and can be promising for developing therapies to combat HCC invasion.
\end{abstract}

Keywords: retinoids; RAR $\alpha$; TFPI2; MAFB; MAFF; hepatocellular carcinoma; invasion

\section{Introduction}

Preclinical studies have shown that retinoids possess anticancer effects against different cancer cell lines in vitro [1-3]. Moreover, it was also demonstrated that retinoids reduced cancer risk by $70 \%$ in animal models [4,5]. The retinoic acid receptor $\alpha(\operatorname{RAR} \alpha)$ is a central mediator of pleiotropic actions of retinoids. Many other factors also take part in retinoid action by modulating the transactivating functions of RAR $\alpha$. For example, a nuclear receptor co-repressor and a short heterodimer partner bind to RAR $\alpha$ and suppress its function [6,7] while SP1 and the B-cell translocation gene 1 activate RAR $\alpha$ via direct interaction $[8,9]$. Since retinoids produce severe side effects including tetracarcinogenesis, mucocutaneous cytotoxicity, and hypertriglyceridemia [10], elucidating the mechanism underlying retinoid-facilitated transcriptional regulation is crucial in developing next-generation retinoid-acting drugs with an improved specificity.

The tissue factor pathway inhibitor 2 (TFPI2) is a serine protease inhibitor that targets the factor VIIa-tissue factor complex as well as trypsin and plasmin [11,12]. TFPI2 indirectly inhibits the activation of the matrix metalloprotease (MMP), which needs trypsin and plasmin and suppresses cancer invasion [13-16]. This antitumor effect is supported by the fact that TFPI2 is silenced in various tumors including hepatocellular carcinoma (HCC) $[15,16]$. Therefore, agents with the ability to restore TFPI2 expression in tumors could be promising for developing novel antitumor drugs. Moreover, 
clarifying the mechanism underlying TFPI2 transcriptional regulation may be helpful in furthering our understanding of tumor development and progression.

In the present study, we aimed to investigate the effect of retinoids on TFPI2 expression and its regulatory mechanism. In addition, we asked whether TFPI2 is involved in retinoid-induced suppression of cancer cell invasion. Finally, it was addressed whether TFPI2 and factors involved in TFPI2 expression affect the prognosis of patients with HCC.

\section{Results}

\subsection{TFPI2 Is Transcriptionally Regulated by ATRA}

Both HuH7 and HepG2 cell lines are derived from highly differentiated human HCC and are functionally similar in many aspects [17]. The mRNA levels of RAR $\beta$, which is a typical retinoid target gene, increased owing to ATRA in both the cell lines in a time-dependent and dose-dependent manner (see Figure 1A,B). However, ATRA increased TFPI2 mRNA levels only in HuH7 cells and not in HepG2 cells (see Figure 1A,C). Note that the TFPI2 gene expresses three transcript variants. The primers for TFPI2 were designed to detect all three variants.

A
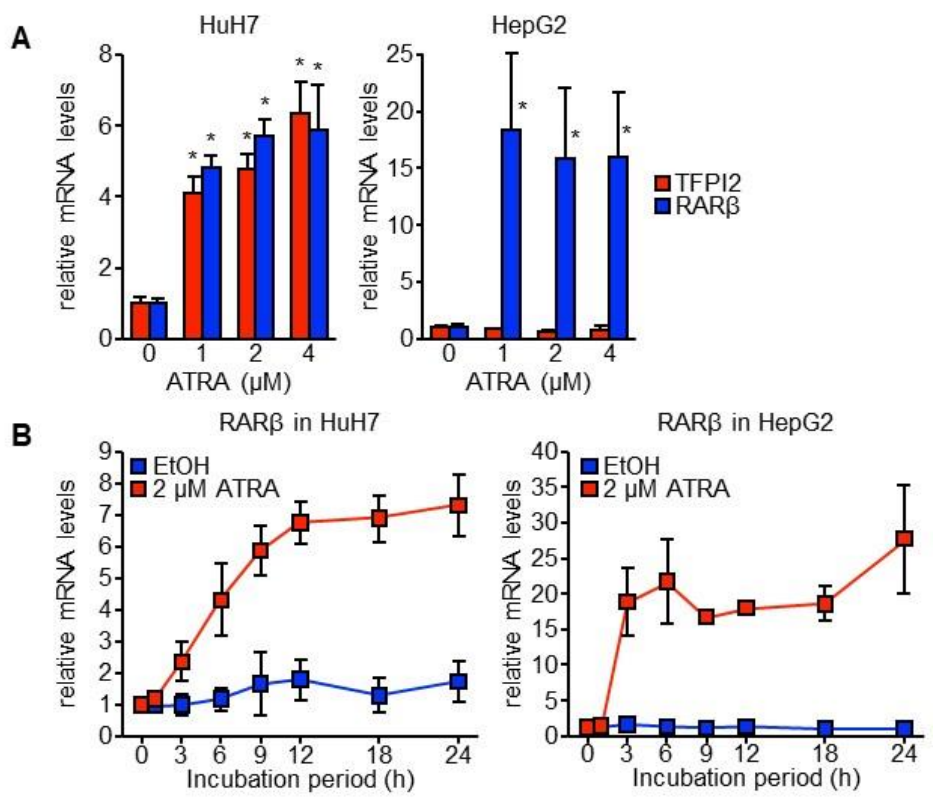

C
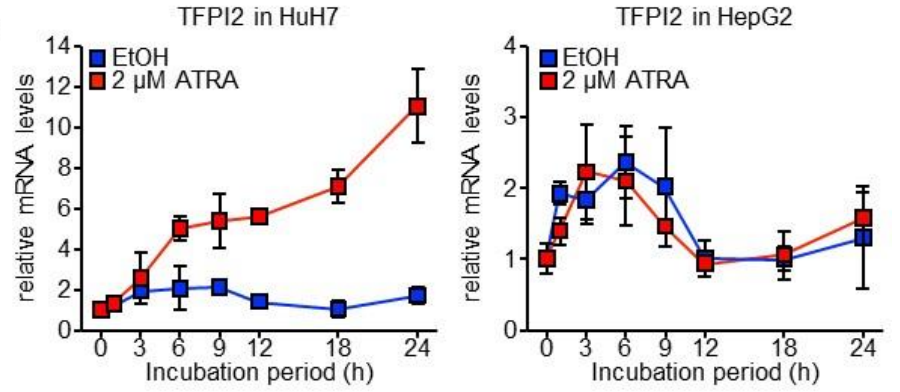

Figure 1. ATRA-induced TFPI2 expression in HuH7 cells. (A) Dose-dependent expression of TFPI2 (red) and RAR $\beta$ (blue) mRNA in HuH7 (left) and HepG2 (right) cells following incubation with ATRA for $12 \mathrm{~h}(n=4) .{ }^{*} p<0.05$ (vs. $0 \mu \mathrm{M}$ ATRA; Dunnett's test), (B,C) Time courses of RAR $\beta$ (B) and TFPI2 (C) mRNA expression in HuH7 (left) and HepG2 (right) cells following incubation with EtOH (blue) and $2 \mu \mathrm{M}$ ATRA (red) for the indicated periods of time $(n=4)$.

The RNA polymerase inhibitor actinomycin D (ActD) was added to the cells with ATRA to investigate whether ATRA increased the stability of TFPI2 mRNA. TFPI2 mRNA was more stable than 
RAR $\beta$ mRNA in both of the HCC cell lines (see Figure 2A,B). However, the increase in TFPI2 mRNA levels due to ATRA in HuH7 cells was abolished by ActD (see Figure 2A), which suggests that ATRA transcriptionally regulates TFPI2 expression.
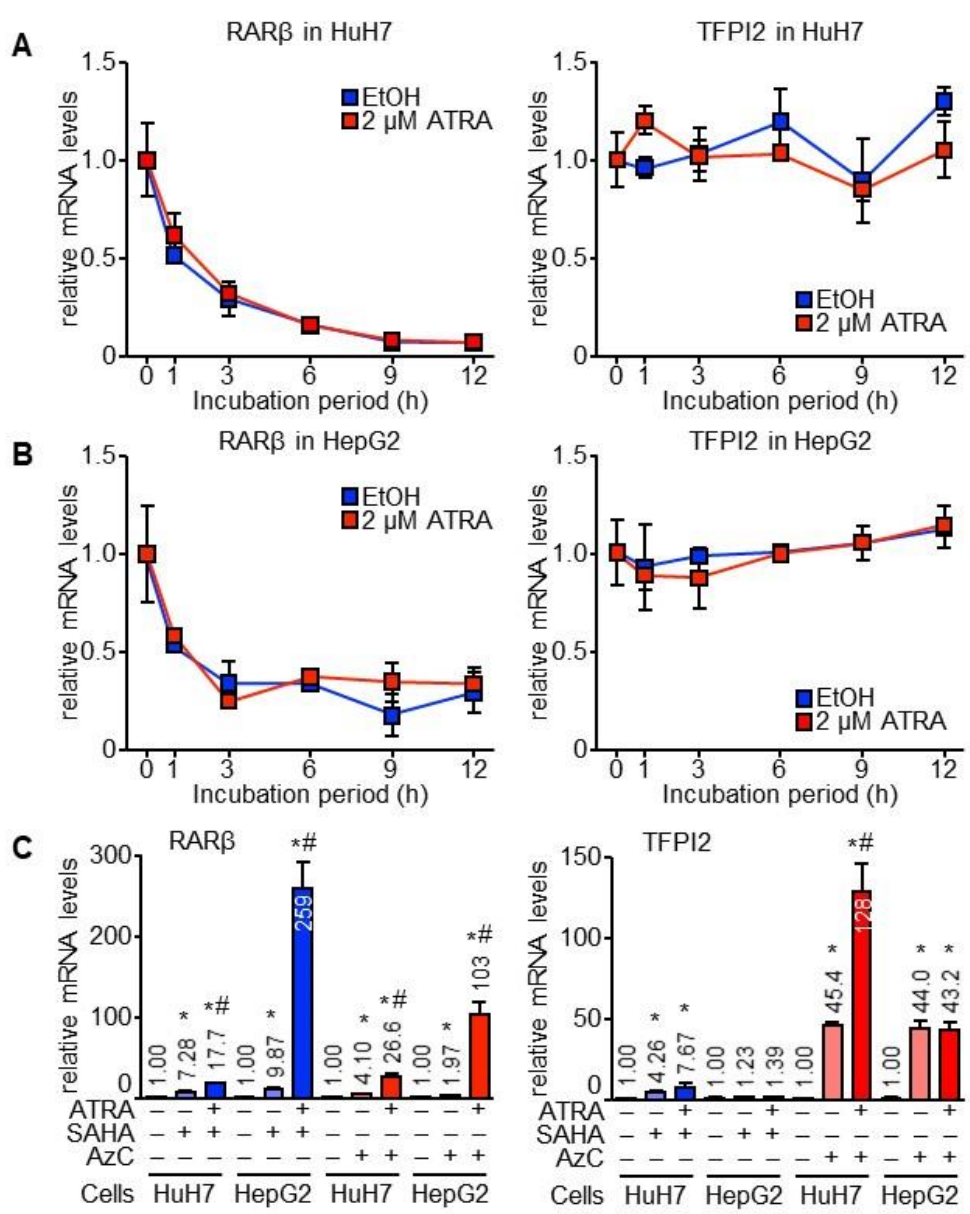

Figure 2. Transcriptional regulation of TFPI2 expression by ATRA in HuH7 cells. (A,B) HuH7 (A) and HepG2 (B) cells pre-treated with ActD incubated with EtOH (blue) and $2 \mu \mathrm{M}$ ATRA (red) for the indicated times. Left, RAR $\beta$, right, TFPI2 $(n=4) ;(C)$ HuH7 and HepG2 cells pre-treated with $N$-hydroxy- $N^{\prime}$-phenyloctanediamide (SAHA) (blue) and AzC (red) incubated with EtOH and $2 \mu \mathrm{M}$ ATRA for $12 \mathrm{~h}$. RAR $\beta$ (Left), TFPI2 (right) $(n=4) .{ }^{*} p<0.05$ (vs. non-treatment control), $\# p<0.05$ (EtOH vs. $2 \mu \mathrm{M}$ ATRA in the presence of SAHA or AzC) (Tukey-Kramer's test).

5-Aza-2'-deoxycytidine (AzC) and $N$-hydroxy- $N^{\prime}$-phenyloctanediamide (SAHA) are inhibitors of DNA methyltransferase and histone deacetylase, respectively. These reagents significantly upregulated RAR $\beta$ expression in both HuH7 and HepG2 cells, which was further boosted by ATRA (see Figure 2C). AzC instead of SAHA induced TFPI2 expression in HepG2, which suggested that epigenetic suppression by DNA methylation was released in the cells. Despite that, ATRA failed to influence TFPI2 expression (see Figure 2C). These results suggest that ATRA-induced TFPI2 expression is independent of the epigenetic mechanisms.

\subsection{Through TFPI2, ATRA Suppresses HuH7 Cell Invasion}

To investigate the biological significance of ATRA-induced TFPI2 expression, TFPI2 was stably knocked down in HuH7 cells using expression vectors of short hairpin RNA (shRNA) targeting TFPI2 (shTFPI2-1 and shTFPI2-2). We also created a control clone transfected with non-targeting shRNA (shNT). These cells were referred to as T2KD-1, T2KD-2, and NT cells, respectively. Although 
ATRA-induced TFPI2 expression was observed in T2KD-1 and T2KD-2 cells, it was decreased by approximately $50 \%$ and $15 \%$, respectively, when compared with that in NT cells (see Figure 3A). The expression of the TFPI2 protein in T2KD-2 cells was also decreased when compared with NT cells and it is upregulated by ATRA, which was observed in NT cells. This was completely abolished in T2KD-2 cells (see Figure 3B). Treatment with ATRA for $48 \mathrm{~h}$ significantly suppressed the invasion of NT cells in a dose-dependent manner while this suppression with respect to T2KD-1 and T2KD-2 cells was significantly impaired, which correlated with the knockdown efficiency (see Figure 3C). Although TFPI2 is responsible for the ATRA-mediated inhibition of $\mathrm{HuH7}$ cell invasion, ATRA also suppressed HepG2 cell invasion without inducing TFPI2 (see Figures 1A and S1), which suggested that ATRA employs several mechanisms to suppress cancer invasion in the context of cell lines.

A
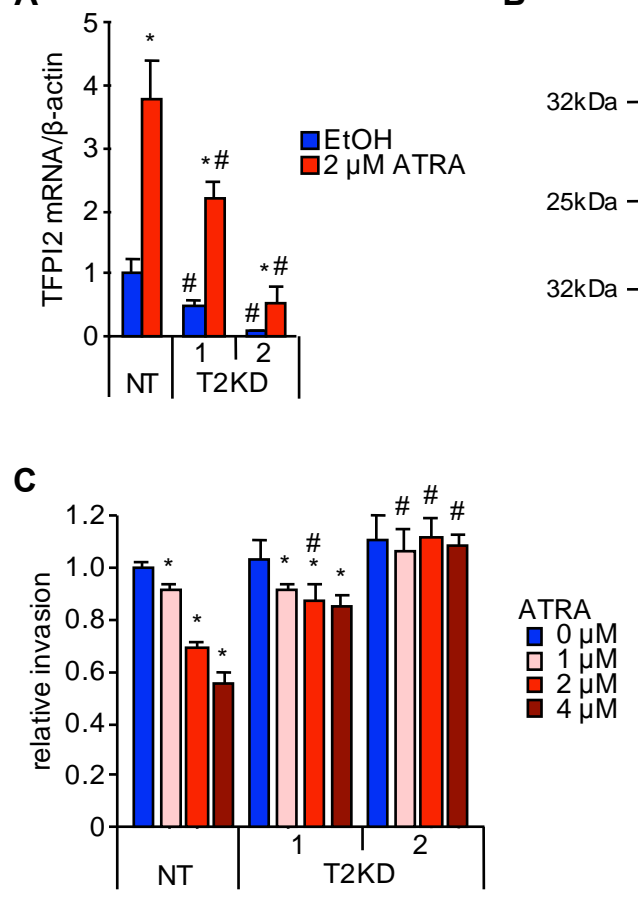

B

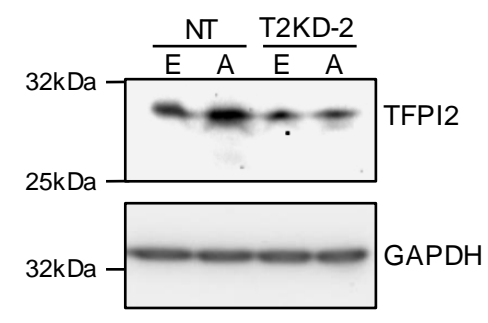

Figure 3. Abrogation of the suppressive effect of ATRA on HuH7 cell invasion by TFPI2 knockdown. (A) TFPI2 mRNA expression in HuH7 cells stably transfected with shNT, shTFPI2-1, and shTFPI2-2 (NT, T2KD-1, and T2KD-2 cells, respectively). The cells were treated with EtOH (blue) and $2 \mu \mathrm{M}$ ATRA (red) for $12 \mathrm{~h}(n=4) .{ }^{*} p<0.05$ (EtOH vs. $2 \mu \mathrm{M}$ ATRA), $\# p<0.05$ (vs. shNT) (Tukey-Kramer's test); (B) TFPI2 expression in NT and T2KD-2 cells. The cells were treated with EtOH (E) and $2 \mu \mathrm{M}$ ATRA (A) for $48 \mathrm{~h}$. Glyceraldehyde-3-phosphate dehydrogenase (GAPDH) was shown as the loading control (C) Invasion capability of NT, T2KD-1, and T2KD-2 cells. The cells were treated with $0 \mu \mathrm{M}$ (blue), $1 \mu \mathrm{M}$ (light red), $2 \mu \mathrm{M}$ (red), and $4 \mu \mathrm{M}$ (dark red) of ATRA for $48 \mathrm{~h}(n=6) .{ }^{*} p<0.05$ (EtOH vs. $2 \mu \mathrm{M}$ ATRA), $\# p<0.05$ (vs. shNT) (Tukey-Kramer's test).

We then performed the microarray analysis to assess the expression profiles of NT and T2KD-2 cells in the presence or absence of $2 \mu \mathrm{M}$ ATRA for 12 and $36 \mathrm{~h}$. In total, 2061 probes and 961 probes with 1.5-fold or more changes in shTFPI2-2 at 12 and $36 \mathrm{~h}$, respectively, were clustered into two groups (Cluster A, shNT > shTFPI2-2 at $12 \mathrm{~h}$, Cluster B, shNT < shTFPI2-2 at $12 \mathrm{~h}$, Cluster C, shNT > shTFPI2-2, $36 \mathrm{~h}$, Cluster D, shNT < shTFPI2-2, $36 \mathrm{~h}$ ) (see Figure S2). This cluster analysis also showed that changes in gene expression induced by ATRA were not markedly different for shNT and shTFPI2-2, which indicated that TFPI2 is a downstream factor of the retinoid signaling. Kyoto Encyclopedia of Genes and Genomes (KEGG) pathway analysis of the clustered genes showed that TFPI2 may be involved in the pathways related to cellular motility (hsa04151, hsa04360, and hsa04510), coagulation (hsa04610), 
nutritional metabolism (hsa00430, hsa01230, hsa01100, hsa00010, hsa00051, hsa01230, and hsa03320), and xenometabolism (hsa00980, hsa00860, hsa00983, hsa05034, and hsa05204) (see Figure S2).

\subsection{MAFB and MAFF Modulate the Transactivation Activity of RAR $\alpha$ on Human TFPI2 Promoter}

Genome-wide binding analysis of musculoaponeurotic fibrosarcoma (MAF) F and MAFK in HepG2 cells from the ENCODE project [18] showed their binding sites in the region around the transcriptional start site of the human TFPI2 (see Figure S3A). This region was inserted upstream of the luciferase gene for reporter assays. RAR $\alpha, R X R \alpha, M A F, M A F A, M A F B$, and MAFG significantly increased the promoter activity while MAFF and MAFK showed no effect (see Figure 4A). Only RAR $\alpha$ showed enhanced transactivation activity in response to ATRA (see Figure 4A). Co-transfection with RXR $\alpha$, MAF, MAFA, and MAFB enhanced the transactivation activity of RAR $\alpha$ while MAFF was suppressed (see Figure 4B). Only MAFB maintained the responsiveness of RAR $\alpha$ to ATRA while the remaining transcription factors abrogated it (see Figure $4 \mathrm{~B}$ ). Therefore, we chose to focus on investigating the effects of MAFB and MAFF on TFPI2 promoter activity. MAFB enhanced the transactivation activity of RXR $\alpha$ only in the presence of ATRA while MAFF showed no effect (see Figure S4A). The effects of MAFB and MAFF on the RXR $\alpha / R A R \alpha$ heterodimer were similar to those on RAR $\alpha$ (see Figure S4A). Co-transfecting MAFB and MAFF showed that the transactivation activity of MAFB remained unaffected by MAFF (see Figure S4B).
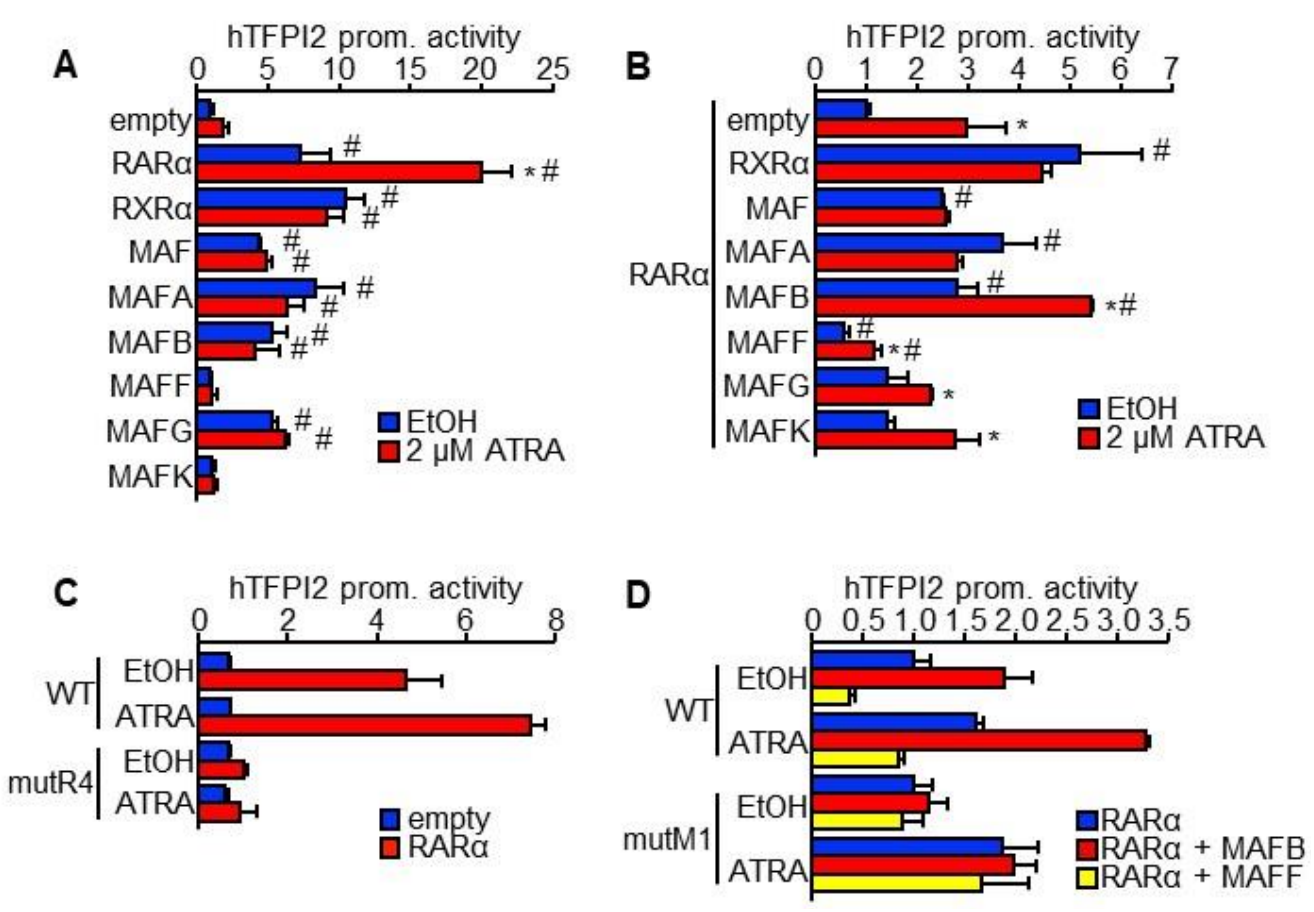

Figure 4. Regulation of human TFPI2 promoter by RAR $\alpha, M A F B$, and MAFF. (A,B) A luciferase reporter vector driven by the human TFPI2 promoter was transfected along with pDNA expressing the indicated transcription factor genes with (B) and without (A) RAR $\alpha$-pDNA into HuH7 cells $(n=4)$. Twenty-four hours after transfection, EtOH (blue) and $2 \mu \mathrm{M}$ ATRA (red) were added to the cells, and further incubated for $24 \mathrm{~h}$, which was followed by dual luciferase assay. ${ }^{*} p<0.05$ (EtOH vs. $2 \mu \mathrm{M}$ ATRA), \# $p<0.05$ (vs. empty) (Tukey-Kramer's test), (C) Luciferase reporter vectors driven by wild-type (WT) and mutant half-site (mutR4) TFPI2 promoters were transfected with empty (blue) and RAR $\alpha$-expressing (red) pDNAs into HuH7 cells $(n=4)$. Twenty-four hours after transfection, EtOH and $2 \mu \mathrm{M}$ ATRA were added to the cells and further incubated for $24 \mathrm{~h}$, which was followed by the dual luciferase assay. (D) Reporter vectors driven by WT or mutant putative MAF binding site (mutM1) TFPI2 promoters were transfected with pDNAs expressing RAR $\alpha$ (blue), RAR $\alpha$ and MAFB (red), or RAR $\alpha$ and MAFF (yellow) into $\mathrm{HuH7}$ cells $(n=4)$. 
In general, RAR $\alpha$ binds to a tandem repeat of the consensus sequence $5^{\prime}$-RGKTCA- ${ }^{\prime}$, which is termed the half-site [19]. However, the repeat sequence was not found in the promoter sequence of human TFPI2. Instead, four half-sites were present (see Figure S3A). In addition, two MAF-binding sites have been predicted by the ORCA toolkit [20]. Therefore, mutations were introduced into each of the four half-sites (mutR1-4) and two putative MAF-biding sites (mutM1-2) (see Figure S3A). The effects of RAR $\alpha$ and MAFB/MAFF on the TFPI2 promoter were, respectively, eliminated by mutR4 and mutM1 even in the presence of ATRA (see Figures 4C,D and S4C,D). These results helped us identify the MAF recognition element (MARE) and retinoic acid response element (RARE) at +6 and +66 relative to the transcription start site, respectively (see Figure S3B). Furthermore, these MARE and RARE were highly conserved among mammalian genomes (see Figure S3B). Binding of RAR $\alpha$ with MAFB or MAFF was not observed under our experimental conditions (see Figure S5). Therefore, MAFB and MAFF might indirectly interact with RAR $\alpha$ on the TFPI2 promoter.

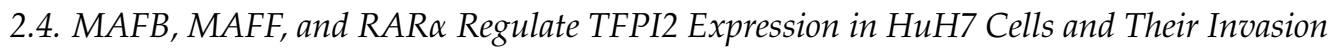

HuH7 cells with stably knocked down RAR $\alpha$ and MAFB (RaKD and MBKD cells, respectively) showed a decreased expression of TFPI2 while those with knocked down MAFF (MFKD) showed an increased TFPI2 expression (see Figures 5A and S6A). Furthermore, HuH7 cells stably overexpressing MAFB (MBOE) showed a marked increase in TFPI2 expression while those overexpressing MAFF (MFOE) showed a decrease (see Figure S6B). ATRA-mediated suppression of cell invasion was significantly impaired by shRAR $\alpha$ and shMAFB while MFKD cells showed a marked reduction in cell invasion irrespective of ATRA (see Figure 5B).
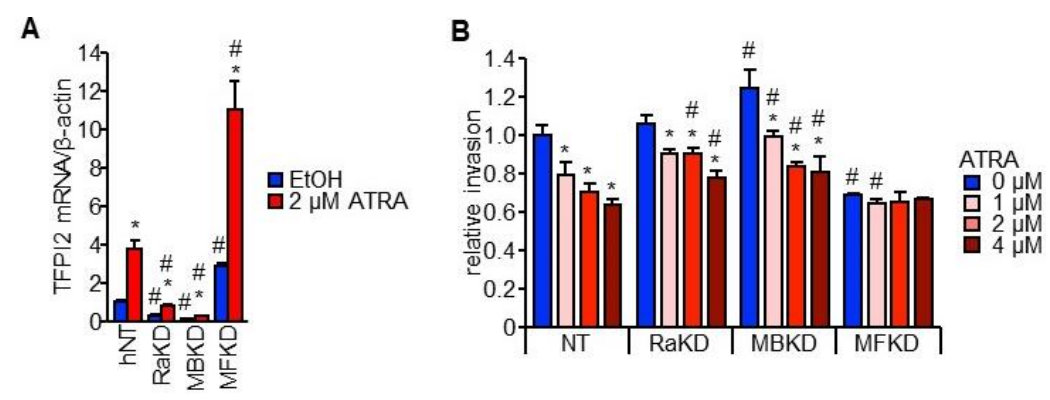

Figure 5. Effect of RAR $\alpha, M A F B$, and MAFF on HuH7 cell invasion through TFPI2. (A) TFPI2 mRNA expression in HuH7 cells stably transfected with $\operatorname{shNT}$, shRAR $\alpha$, shMAFB, or shMAFF (NT, RaKD, MBKD, and MFKD cells, respectively). The cells were treated with EtOH (blue) or $2 \mu \mathrm{M}$ ATRA (red) for $12 \mathrm{~h}(n=4) .{ }^{*} p<0.05$ (EtOH vs. $2 \mu \mathrm{M}$ ATRA), \# $p<0.05$ (vs. shNT) (Tukey-Kramer's test); (B) Invasion capability of HuH7 cells stably transfected with shNT, shRAR $\alpha$, shMAFB, or shMAFF. The cells were treated with $0 \mu \mathrm{M}$ (blue), $1 \mu \mathrm{M}$ (light red), $2 \mu \mathrm{M}$ (red), and $4 \mu \mathrm{M}$ (dark red) of ATRA for $48 \mathrm{~h}(n=8)$. * $p<0.05$ (vs. $0 \mu \mathrm{M}$ ATRA), \# $p<0.05$ (vs. shNT) (Tukey-Kramer's test).

\subsection{RAR $\alpha$ and MAFB Contribute to the Downregulation of TFPI2 in HCC}

We checked whether the factors involved in TFPI2 transcription plays a role in human HCC. We performed quantitative PCR with 44 cDNA samples derived from eight normal, five fatty, three hepatitis, five cirrhotic, and 23 HCC liver tissues (see Table S1). The expression of TFPI2, RAR $\beta$, MAFB, and MAFF was significantly lower in HCC than that in normal liver tissue (see Figure 6). MAFB expression was also downregulated in fatty and cirrhotic liver tissues. The role of epigenetic mechanisms aside, the downregulation of TFPI2 can be attributable to the decreased expression of RAR $\beta$ and MAFB in HCC. Correlation analysis demonstrated that the mRNA expression of TFPI2 in the clinical samples was significantly correlated with those of MAFB and MAFF (see Figure S7). Taking into account the observation that MAFF did not affect MAFB-induced activation of the TFPI2 promoter (see Figure S4B), MAFB may play a more important role in hepatic TFPI2 expression than 
the other transcription factors. Furthermore, MAFB and RAR $\alpha$ expression in HCC was significantly downregulated as the TNM stage and histological grade increased while no correlation between TFPI2 and tumor grades was observed (see Table S2).
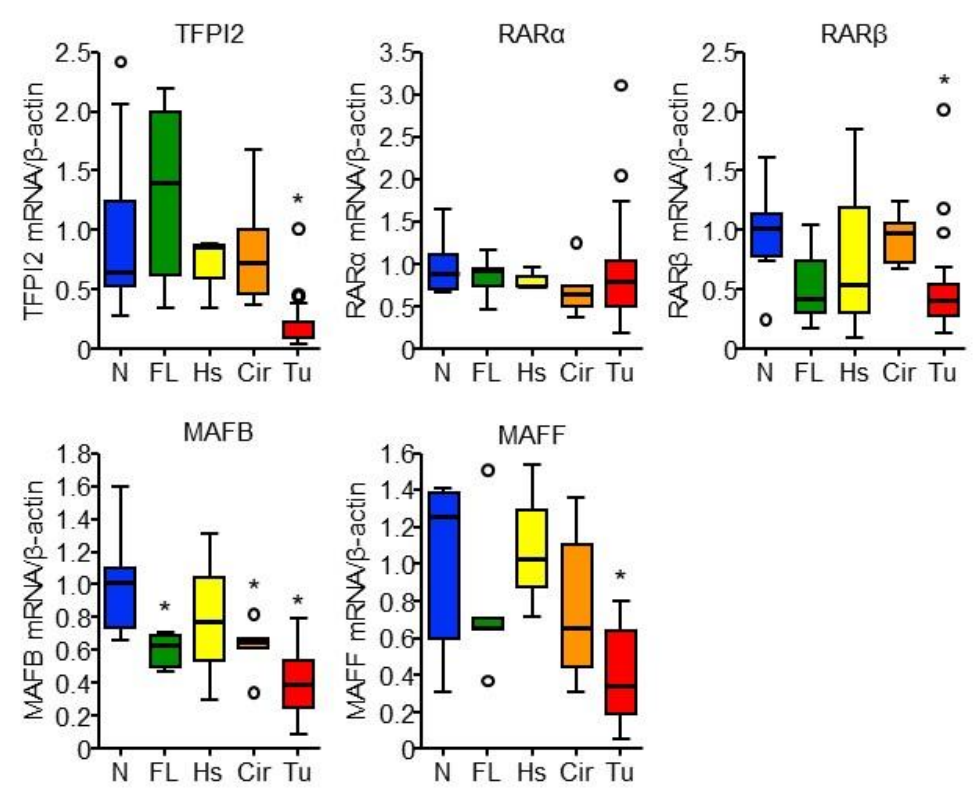

Figure 6. Gene expression in different types of liver diseases. Box and whisker plots of relative gene expression levels of TFPI2, RAR $\alpha, \operatorname{RAR} \beta, \mathrm{MAFB}$, and MAFF to $\beta$-actin in normal (N, $n=8$; blue), fatty (FL, $n=5$; green), hepatitis (Hs, $n=3$; yellow), cirrhotic (Cir, $n=5$; orange), and hepatocellular carcinoma ( $\mathrm{Tu}, n=23$; red) liver tissues. Boxes indicate first and third quartiles and median values and whiskers represent 5 and 95 percentiles. Open circulars indicate outliers. ${ }^{*} p<0.05$ (vs. normal liver tissues) (Dunnett's test).

\subsection{Involvement of MAFB, MAFF, and TFPI2 in the Progression and Prognosis of HCC}

We further analyzed gene expression in patients with HCC by using the data generated by the TCGA Research [21]. HCC patients with vascular invasion showed significantly low MAFB expression while other genes remained unaffected (see Figure 7A). In addition, the expression of TFPI2 and RAR $\beta$ was significantly low in patients with metastasis (see Figure 7B). This suggests that these genes may impact the prognosis of HCC patients.
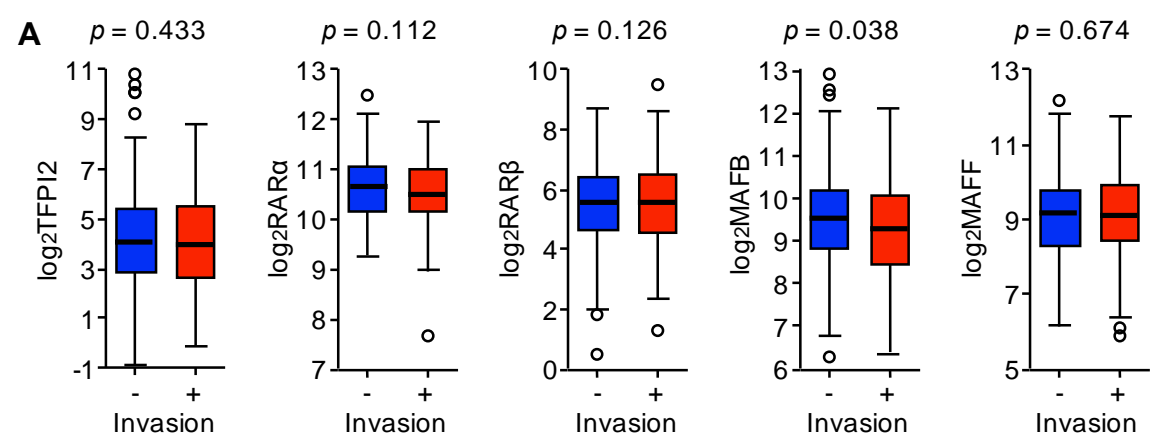

Figure 7. Cont. 

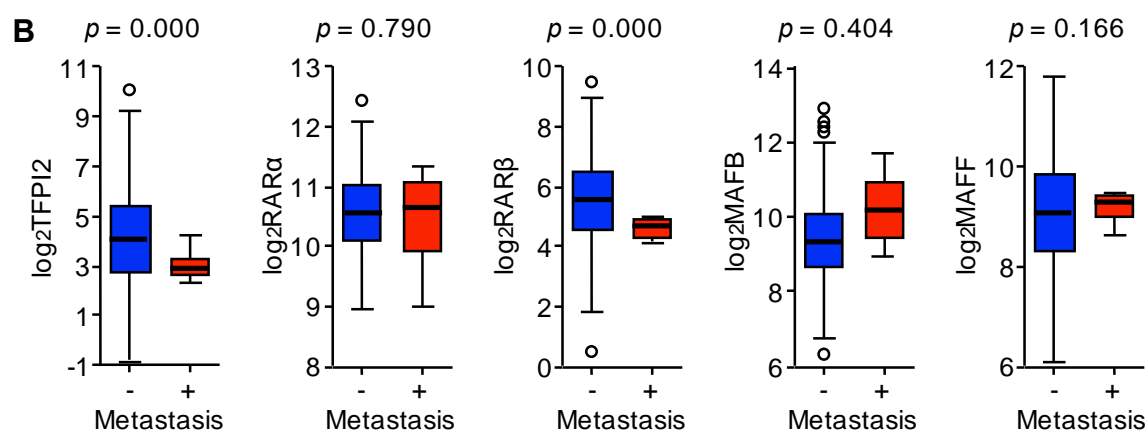

Figure 7. Correlation of gene expression in the livers of patients with HCC with vascular invasion and metastasis from the TCGA cohort. (A) Box and whisker plots of log 2 gene expression levels in HCC livers with (red) or without (blue) vascular invasion (TFPI2, $n=108$ vs. 204, RAR $\alpha$, RAR $\beta$, MAFB, MAFF, $n=109$ vs. 207). (B) Box and whisker plots of log 2 gene expression levels in HCC livers with (red) or without (blue) metastasis ( $n=4$ vs. 267). Boxes indicate first and third quartiles and median values and whiskers represent 5 and 95 percentiles. Open circulars indicate outliers. $p$ values shown were calculated by the Welch's $t$-test.

Kaplan-Meier analysis revealed that the expression of TFPI2, RAR $\alpha, \operatorname{RAR} \beta, \mathrm{MAFB}$, and MAFF does not influence the disease-free survival (DFS) period (see Figure S8 [22]). However, patients with high MAFB expression in TFPI2 high or MAFF high groups showed longer DFS period than those with low MAFB expression (see Figures 8A,B and S8B). In contrast, patients with high MAFF expression in TFPI2 low or MAFB low groups showed poorer DFS than those with low MAFF expression (see Figures 8C,D and S8B). There was no significant difference among other groups including RAR $\alpha$ and RAR $\beta$ (see Figure S8B [22]).
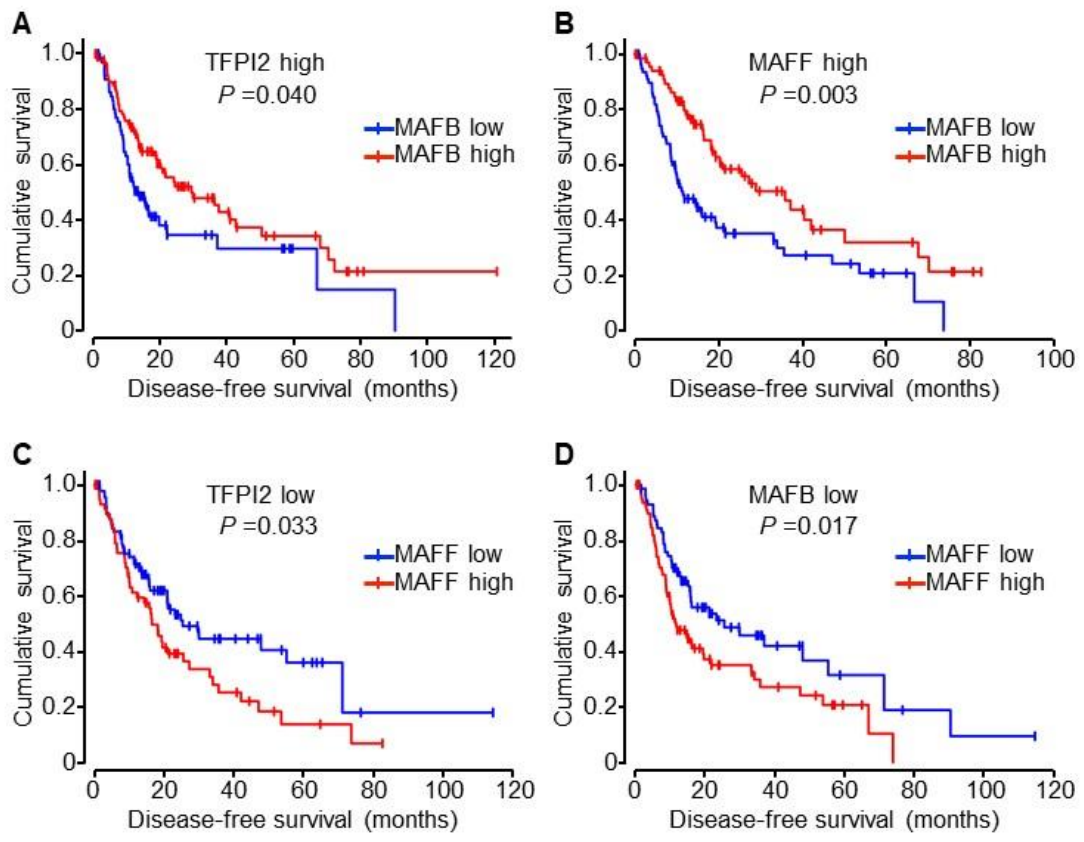

Figure 8. Kaplan-Meier analyses of disease-free survival of HCC patients from the TCGA cohort. $(\mathbf{A}, \mathbf{B})$ Disease-free survival curves of patients with lower (blue) or higher (red) MAFB expression in HCC with higher TFPI2 ( $n=68$ or $n=93$, respectively) (A) or higher MAFF ( $n=83$ or 70, respectively) (B) groups, (C,D) Disease-free survival curves of patients with lower (blue) or higher (red) MAFF expression in HCC with lower TFPI2 ( $n=94$ or $n=62$, respectively) (C) or lower MAFB ( $n=73$ or $n=83$, respectively) (D) groups. $P$ values shown were calculated by log-rank test. Median values of gene expression were used to divide the patients into the higher or lower groups. 


\subsection{Biological Significance of MAFB-Regulated ATRA Target Genes}

The above findings in human HCC suggest anti-oncogenic properties of MAFB against MAFF. This prompted us to perform a microarray analysis by using the MAFB-knockdown and MAFF-knockdown HuH7 cells (MBKD and MFKD cells, Figure S6A). The genes showing expression that was 1.5-fold or higher due to ATRA in all cell lines were analyzed and clustered into six groups (see Figure S9). Clusters A and D contained genes whose induction ratio was increased and decreased by shMAFF, which implies that retinoid-target genes are regulated by MAFF (see Figure S9A). Clusters $\mathrm{B}$ and $\mathrm{E}$, respectively, comprised retinoid-target genes that were positively and negatively regulated by MAFB (see Figure S9A). The genes in clusters $C$ and $F$ were, respectively, thought to be positively and negatively regulated by MAFB and MAFF. There was no cluster indicating genes regulated by MAFB and MAFF in an inverse manner (see Figure S9A).

The KEGG pathway analysis showed that the enriched pathways common to MAFB and MAFF were retinol metabolism (hsa0083) and the adipocytokine signaling pathway (hsa04920) (see Figure S9B). In addition, MAFB was thought to be involved in coagulation (hsa04610) and MAFF in the inflammatory response (hsa04668, hsa04064, and hsa04670) (see Figure S9B).

\section{Discussion}

MAF transcription factor family members play a vital role in various biological processes. They are divided into two groups based on structural characteristics including large MAFs, which involve c-MAF, MAFA, and MAFB, and small MAFs, which include MAFF, MAFG, and MAFK (see review [23]). Since small MAFs lack the transactivation domain, they can positively and negatively regulate transcription depending on their dimerization partners [24].

In the liver, small MAFs generally form a heterodimer with the Cap'n'Collar proteins to regulate cytoprotective genes related to xenobiotic metabolism, the oxidative stress response, and the redox homeostasis [24]. MAFG was recently revealed as a transcriptional repressor of bile acid synthesis and metabolism [25]. Although mice that lack only one of the small MAFs are viable and show mild phenotypic changes, knockout of all three small MAFs result in embryonic lethality with severe hypoplasia in the fetal liver due to increased apoptosis of hepatocytes and erythrocytes [26]. This suggests that despite being functionally redundant, small MAFs are crucial in proper liver development.

MAFB plays a role in the development of erythrocytes, pancreatic $\beta$ cells, renal podocytes, and macrophages in the fetal liver [27-29]. The anti-oncogenic potential of MAFB is not entirely clear and tends to depend on the cellular context. Additionally, downregulation of MAFB expression is observed in neoplastic liver lesions induced by the activation of $\gamma$-aminobutyric acid A receptor in an $\mathrm{N}$-diethylnitrosamine-induced hepatocarcinogenesis model [30]. By contrast, MAFB overexpression in hematopoietic stem/progenitor cells leads to the development of leukemia and myeloma [31]. Although MAFB transforms primary fibroblasts with an efficiency lower than that of c-MAF and MAFA [32], large MAFs do not transform chicken embryonic neuroretina cells but rather induce differentiation of crystallin-producing cells and counteract the proliferation of mutant RAS-transformed neuroretina cells [33]. In addition, MAFB induces the differentiation into macrophages of transformed hematopoietic precursor cells. c-MAF is thought to act as a tumor suppressor gene in prostate cancer $[34,35]$.

We therefore hypothesized that MAFB confers its anti-oncogenic effects by antagonizing MAFF since MAFB-induced activation of the TFPI2 promoter remained unaffected by MAFF (see Figure S4B). Furthermore, the expression of MAFB in HCC tissues was significantly downregulated as the tumor stage increased (see Table S2). By contrast, the apparent difference in MAFB and MAFF expression was not observed in the presence or absence of vascular invasion or metastasis and there were no differences in DFS time based on individual gene expression. This might be attributable to the functional redundancy of large as well as small MAFs. However, HCC patients with lower MAFB and higher MAFF expression (median DFS time: 11.5 months) showed poorer DFS than those with 
higher expression of both MAFB and MAFF (35.8 months, $p=0.003)$ and those with lower expression of both MAFB and MAFF (25.3 months, $p=0.017$ ) (see Figures 8B,D and S8B). This suggests that MAFF functions as an oncogene in the absence of MAFB. Therefore, the complex interaction of MAFs must be considered when attempting to understand the physiological functions of MAFs in patients with HCC.

To our knowledge, this is the first report demonstrating the regulatory function of MAFB and MAFF in HCC cell invasion. TFPI2 is well known as a tumor suppressor gene and inhibits not only the factor VIIa/tissue factor complex but also plasmin, kallikrein, and trypsin [12]. By virtue of this property, TFPI2 also inhibits the activation of MMP1 and 3 by plasmin and trypsin [16]. However, Neaud et al. reported that TFPI2 showed a pro-invasive effect on HCC cell lines, which includes HepG2 and HuH7 cells [36]. They also demonstrated that the neutralization of factor VII with its specific antibody abolished the TFPI2-induced invasion of HCC cell lines [36]. The reason for this discrepancy is not clear at present. Our pathway analysis suggested that knockdown of TFPI2 in HuH7 cells influences the coagulation pathway (see cluster D in Figure S2). In addition, retinoid-target genes regulated by MAFB were also suggested to be classified into the coagulation pathway (clusters B \& $\mathrm{E}$ in Figure S9). The modulation of clotting factor expression by ATRA may underlie the discrepancy effects of TFPI2 on cancer cell invasion.

Furthermore, the expression of TFPI2 is frequently silenced by promoter methylation in many tumor tissues including HCC $[15,16,37,38]$. Therefore, the restoration of TFPI2 expression suppresses the invasiveness of malignant tumors [16]. In contrast to the silencing mechanism, the transcription factors that are involved in TFPI2 transcription have not been well studied. In the present study, we identified the members belonging to the MAF transcription factor family as novel regulators of RAR $\alpha$ transactivation activity in TFPI2 expression. We did not observe ATRA-induced TFPI2 expression in HepG2 cells (see Figure 1A). This may be explained by relatively low expression of MAFB in HepG2 cells when compared with HuH7 cells (see Figure S10A). The reporter assay in HepG2 cells demonstrated that RAR $\alpha$ as well as MAFB and MAFF did not markedly affected TFPI2 promoter activity even in the presence of ATRA (see Figure S10B). However, when co-transfected MAFB or MAFF with RAR $\alpha$, MAFB significantly activated the promoter while MAFF suppressed it, which was observed in HuH7 cells (see Figure S10B). Therefore, it is implied that MAFB expression in HepG2 cells may not be sufficient for RAR $\alpha$ to induce TFPI2 expression.

By dividing the HCC patients into groups with higher or lower TFPI2 expression, it was seen that in the higher TFPI2 group, those with higher MAFB expression showed better DFS than those with lower MAFB expression (29.3 months vs. 12.9 months, $p=0.040$ ) while, in the lower TFPI2 group, those with lower MAFF showed better DFS than those with higher MAFF expression (25.3 months vs. 16.5 months, $p=0.033$ ) (see Figure 7A,C and Figure S8B). These results suggest that MAFB and MAFF determine TFPI2 expression along with the epigenetic mechanisms. The limitations of our study include the inability to ascertain the correlation between RAR $\alpha$ expression and HCC malignancy in combination with the expression of other genes. Low body retinoid stores are frequently observed in patients with chronic liver diseases including those with HCC $[39,40]$. It has also been shown that retinoid supplementation significantly improves the prognosis of patients with the hepatitis $C$ virus-related HCC [41]. Therefore, it is likely that the activation of RAR $\alpha$ by administration of retinoids possibly provides this benefit through TFPI2.

To summarize, TFPI2 is an anti-oncogene suppressing HCC invasion whose expression is regulated epigenetically and by retinoids. Moreover, MAFB and MAFF are novel regulators of RAR $\alpha$ at least with respect to the transcription of TFPI2 (see Figure S11). This system may be implicated in the pathogenesis and progression of HCC and can be promising as a target for preventing and treating HCC in addition to predicting HCC prognosis. 


\section{Materials and Methods}

\subsection{Materials}

The HuH7, HepG2, and KMST-6 cells, in addition to the plasmid DNAs (pDNAs) expressing human $\operatorname{RXR} \alpha$ and MAFG, were purchased from the RIKEN BRC (Tsukuba, Japan) through the National Bio-Resource Project of the MEXT, Japan. The PDNA-expressing mouse Maf and those expressing mouse MafA or MafB were kindly provided by Hiroshi Nakajima (Graduate School of Medicine, Chiba University, Chiba, Japan) [42] and Satoru Takahashi (Faculty of Medicine, University of Tsukuba, Tsukuba, Japan) $[43,44]$. PDNAs expressing MAFF, MAFK, and RAR $\alpha$ were obtained from NITE Biological Resource Center (Kisarazu, Japan). ShRNA expression vectors targeting TFPI2 (shTFPI2-1, TRCN0000072723; shTFPI2-2, TRCN0000072726), RAR $\alpha$ (shRAR $\alpha$, TRCN0000020373), MAFB (shMAFB, TRCN0000017680), and MAFF (shMAFF, TRCN0000016448) along with pLKO.1-puro Non-Target shRNA (shNT) and fetal bovine serum (FBS), which were purchased from Sigma-Aldrich (St. Louis, MO, USA). Dual luciferase assay reagents and luciferase-expressing pDNAs were acquired from Promega (Madison, WI, USA). The cell invasion assay kit (medium basement membrane extract), QuikChange Lightning Site-Directed Mutagenesis Kit, and Viofectin transfection reagent were respectively purchased from Trevigen, Inc. (Gaithersburg, MD, USA), Agilent Technologies (Santa Clara, CA, USA), and Viogene (New Taipei City, Taiwan). ReverTra Ace, Thunderbird SYBR qPCR Mix, and KOD-Plus-Neo were purchased from Toyobo Co., Ltd. (Osaka, Japan). The Anti-Flag antibody and its magnetic agarose beads were purchased from MBL (Nagoya, Japan) and anti-Strep-tag II (ab76949) and anti-TFPI2 (ab186747) antibodies from Abcam (Cambridge, UK). ATRA and anti-GAPDH antibody (sc-365062) was purchased from Santa Cruz Biotechnology (Santa Cruz, CA, USA). Dulbecco's modified Eagle's medium (DMEM), ActD, ethanol (EtOH), puromycin, G418, and Sepasol-RNA I super G were purchased from Nacalai Tesque Inc. (Kyoto, Japan). AzC and SAHA were bought from Tokyo Chemical Industry Co., Ltd. (Tokyo, Japan).

\subsection{Cell Culture and ATRA Treatments}

$\mathrm{HuH7}$ and HepG2 cells were cultured in DMEM supplemented with $10 \%$ FBS at $37{ }^{\circ} \mathrm{C}$ with $5 \%$ $\mathrm{CO}_{2}$. Four milliliters of ATRA stock solution was prepared with EtOH. When treating the cells with ATRA, the same volume of EtOH was added to control cells at a concentration of $<0.1 \%$.

\subsection{Treatment with ActD, AzC, and SAHA}

To suppress transcription, HuH7 and HepG2 cells were pre-treated with $5 \mu \mathrm{g} / \mathrm{mL}$ ActD for 30 min after which they were separately incubated with EtOH and $2 \mu \mathrm{M}$ ATRA for 0 to $12 \mathrm{~h}$. To check whether epigenetic mechanisms were involved, HuH7 and HepG2 cells were pre-treated with $2 \mu \mathrm{M}$ SAHA for $36 \mathrm{~h}$ or with $2 \mu \mathrm{M} \mathrm{AzC}$ for $108 \mathrm{~h}$ after which the cells were separately incubated with EtOH and $2 \mu \mathrm{M}$ ATRA for $12 \mathrm{~h}$ in the presence of SAHA or AzC.

\subsection{Establishment of Transgenic Cell Lines}

$\mathrm{HuH7}$ cells were transfected with pDNAs of $\operatorname{shNT}$, shTFPI2, $\operatorname{shRAR} \alpha, \operatorname{shMAFB}$, and shMAFF by Viofectin, which was followed by puromycin selection. HuH7 cells transfected with empty pDNA, pDNA expressing mouse MAFB, or human MAFF were selected by G418. Gene expression in isolated clones was analyzed by using reverse-transcription quantitative PCR.

\subsection{Determination of $m R N A$ Levels}

The cells were lysed with sepazol and total RNA was purified according to the manufacturer's instructions. Complementary DNA (cDNA) was synthesized with ReverTra Ace and was analyzed by quantitative PCR with Thunderbird SYBR qPCR Mix. The following PCR primers were used: $\beta$-actin, GATGCAGAAGGAGATCACTGC (sense) and TGATCCACATCTGCTGGAAG (anti-sense); TFPI2, 
GAACCTGTGATGCTTTCACC (sense) and TCCGGATTCTACTGGCAAAG (anti-sense); MAFB, TGAACTTTGCGCGTTAAGCC (sense) and TCCTTTCCTCGTTGCTCTCTTC (anti-sense); mouse MAFB, AGTCGTGCAGGTATAAACGC (sense) and GAGTTTCTCGCACTTGACCTTG (anti-sense); MAFF, ATCCCCTATCCAGCAAAGCTC (sense) and TTGAGCCGTGTCACCTCCTC (anti-sense); RAR $\alpha$, CATTGAGAAGGTGCGCAAAG (sense) and AGACACGTTGTTCTGAGCTG (anti-sense); RARB, GAAAAAGACGACCCAGCAAG (sense) and ATGAGAGGTGGCATTGATCC (anti-sense). Relative mRNA levels were measured using the $2^{-\Delta \Delta C t}$ method with $\beta$-actin as an internal control.

\subsection{Cell Invasion Assay}

Cells pre-cultured in serum-free DMEM for $24 \mathrm{~h}$ were seeded in top chambers containing a medium amount of basement membrane extract and were incubated in serum-free DMEM supplemented with $0-4 \mu \mathrm{M}$ of ATRA for $48 \mathrm{~h}$ while the bottom chambers were filled with DMEM containing $10 \%$ FBS as well as the same concentration of ATRA. After the incubation, the cells remaining in the top chambers were discarded and invasive cells were recovered using a dissociation solution provided through the cell invasion assay kit. The recovered cells were stained with calcein AM and calcein fluorescence was measured at an excitation of $485 \mathrm{~nm}$ and an emission of $520 \mathrm{~nm}$.

\subsection{Dual Reporter Assay}

To construct a human TFPI2 promoter reporter vector, PCR cloning was performed with LA Taq with GC buffer I (TaKaRa Bio, Otsu, Japan). In the reaction, genomic DNA isolated from a human immortalized the fibroblast cell line, KMST-6, was used as a template and the following oligoDNAs were used as primers: hTFPI2pro-For, CGTCCTCGAGGTCCACACAAAGCAGCTT; hTFPI2pro-Rev, GTCGAGATCTGGGCAAGGCGTCCGAGAAA. The PCR products were digested with XhoI and BgIII, which was followed by ligation into the same restriction sites of pGL4.10 [luc2]. The promoter sequence was confirmed by DNA sequencing. Site-directed mutagenesis was performed according to the manufacturer's instructions by using the following mutagenic primers: mutR1-For, GTGCG GAGTTCTTGGAAAAGAGCGGAGCGGGATTCG; mutR1-Rev, CGAATCCCGCTCCGCTCTTTTCCA AGAACTCCGCAC; mutR2-For, CCACCTCTTGAAGGCATGAAGAAAAGGTATTTGAAAGGCT GGTGG; mutR2-Rev, CCACCAGCCTTTCAAATACCTTTTCTTCATGCCTTCAAGAGGTGG; mutR3-For, TGGGAAATCTGCAAGCTAGACGGAAAAAGAATGCTAGTGATTGCGCTGTAAAG AAGC; mutR3-Rev, GCTTCTTTACAGCGCAATCACTAGCATTCTTTTTCCGTCTAGCTTGCAGATTT CCCA; mutR4-For, CCCCGCCAAGTTGAAAAGTTTTTCCTGCCTCCCAAACTTTCTC; mutR4-Rev, GAGAAAGTTTGGGAGGCAGGAAAAACTTTTCAACTTGGCGGGG; mutM1-For, CTAGCTTGCAG ATTTCCCATTACTTTCCAAAACGCTCCCTCAGGGCG; mutM1-Rev, CGCCCTGAGGGAGCGTTTT GGAAAGTAATGGGAAATCTGCAAGCTAG; mutM2-For, GCGGGGTGACAGTCCCCGTGCATTTA ATAGCCACCCCTCA; mutM2-Rev, TGAGGGGTGGCTATTAAATGCACGGGGACTGTCACCCCGC.

These reporter vectors and pDNAs expressing transcription factors were transfected into $\mathrm{HuH7}$ cells using Viofectin. The dual luciferase assay was performed $48 \mathrm{~h}$ after transfection using pGL4.74[hRluc/TK] expressing renilla luciferase with the herpes simplex virus thymidine kinase promoter (Promega) acting as a transfection control.

\subsection{Gene Expression Data in Clinical Samples}

CDNAs derived from various liver tissues (TissueScan Liver Cancer Tissue qPCR Panel I) were purchased from Origene Technologies (Rockville, MD, USA). RNA-seq data of HCC tissues were obtained from the TCGA Research Network [21], which also provides DFS times, and the presence of vascular invasion or metastasis.

\subsection{Transcription Profiling}

MRNAs were recovered from cells treated with EtOH or $2 \mu \mathrm{M}$ ATRA for $12 \mathrm{~h}$ by using sepazol and were purified with the RNeasy Plus Mini Kit (QIAGEN, Redwood City, CA, USA). The expression 
profile was analyzed by the Human HT-12 v4 Expression BeadChip (Illumina, San Diego, CA, USA) at Macrogen Japan (Kyoto, Japan). The microarray data were deposited in the ArrayExpress database (Accession No. E-MTAB-6447). Cluster analysis was performed using Cluster 3.0 and the results were visualized using Java Tree View. The Database for Annotation, Visualization, and Integrated Discovery online tool was used to enrich the Kyoto Encyclopedia of Genes and Genomes (KEGG) pathway.

\subsection{Immunoprecipitation-Western Blotting}

PDNA expressing Strep-tag-fused RAR $\alpha$ was constructed as follows. Internal ribosome entry site of pIRES2 DsRed-Express2 (Clontech, Foster City, CA, USA) was amplified by KOD-Plus-Neo with the forward primer, GCGGGTCGACGCCССTCTCССТCССC, and the reverse primer, GCGGGG ATCCTGTGGCCATATTATCATCGT. The PCR product was digested with SalI and BamHI and was then ligated into the same restriction sites of pAcGFP-N1 (Clontech), which produced pIRES2-AcGFP. RAR $\alpha$ cDNA was amplified by using pDNA expressing human RAR $\alpha$ as a template with the forward primer, GGCGCTCGAGCACTGTTGGCCTACTGG, and the reverse primer, CGCCGAATTCTT ACTTTTCAAACTGCGGATGGCTCCACGGGGAGTGGGTGGCCG, which fuses a Strep tag to the C-terminal of RAR $\alpha$. The PCR product was digested with XhoI and EcoRI and was then ligated into the same restriction sites of pIRES2-AcGFP. This resulted in a pDNA expressing Strep-tag-fused RAR $\alpha$.

PDNAs expressing Flag-tag-fused MafB and MAFF were constructed as follows. Mouse MafB and human MAFF cDNAs were amplified by KOD-Plus-Neo with the MafB forward primer, GGCGGCTAGCCACCATGGACTACAAGGATGACGATGACAAGATGGCCGCGGAGCTGAGC, which fuses a Flag tag to the N-terminal of MafB and the MafB reverse primer, CGCCGTCGACTC ACAGAAAGAACTCAGGAGAG, in addition to the MAFF forward primer, GGCGGCTAGCCAC CATGGACTACAAGGATGACGATGACAAGATGTCTGTGGATCCCCTATC, which fuses a Flag tag to the N-terminal of MAFF and the MAFF reverse primer, GGGGGTCGACTAGGAGCAGGAGGCCGGG. The PCR products were digested with NheI and SalI and were then ligated into the same restriction sites of pIRES2 DsRed-Express2, which result in pDNAs expressing Flag-tag-fused MAFB and MAFF.

The pDNA expressing Strep-tag-fused RAR $\alpha$ was co-transfected into HEK293 cells with either empty pDNA or pDNAs expressing Flag-tag-fused MAFB or MAFF. Forty-two hours after transfection, EtOH and $2 \mu \mathrm{M}$ ATRA were separately added to the cell mixture. Following a six hour incubation, the cells were lysed with NP40 buffer (1\% NP40, $50 \mathrm{mM}$ Tris- $\mathrm{HCl}[\mathrm{pH}$ 8.0] and $150 \mathrm{mM} \mathrm{NaCl})$. The lysates were incubated overnight with anti-Flag-tag antibody-conjugated magnetic beads at $4{ }^{\circ} \mathrm{C}$. The whole-cell lysates and precipitates were separated by using SDS-PAGE and immunoblotting with anti-Strep-tag and anti-Flag-tag antibodies.

\subsection{Statistical Analysis}

Data were expressed as mean \pm standard deviation. Statistical analysis was performed using SPSS (version 24, SPSS Inc., Chicago, IL, USA). Probability values less than 0.05 were considered statistically significant.

Supplementary Materials: Supplementary materials can be found at http:/ /www.mdpi.com/1422-0067/19/5/ 1450/s1.

Author Contributions: H.T. designed and supervised experiments, analyzed and interpreted data, and wrote the manuscript. H.T. and S.O. performed the experiments.

Acknowledgments: The authors express gratitude to Hiroshi Nakajima (Graduate School of Medicine, Chiba University, Japan) and Satoru Takahashi (Faculty of Medicine, University of Tsukuba, Japan) for kindly providing us mouse Maf-expressing pDNA and mouse MafA- expressing pDNAs or MafB-expressing pDNAs, respectively. This work was supported by JSPS KAKENHI Grant Number JP16K09359, the Mochida Memorial Foundation for Medical and Pharmaceutical Research, the Kowa Life Science Foundation, and the Takeda Science Foundation (H.T.).

Conflicts of Interest: The authors have no competing financial interest. 


\section{Abbreviations}

$\begin{array}{ll}\text { RAR } \alpha & \text { retinoic acid receptor } \alpha \\ \text { TFPI2 } & \text { tissue factor pathway inhibitor } 2 \\ \text { HCC } & \text { hepatocellular carcinoma } \\ \text { ATRA } & \text { all-trans-retinoic acid } \\ \text { MAFB } & \text { musculoaponeurotic fibrosarcoma oncogene homolog B } \\ \text { MAFF } & \text { musculoaponeurotic fibrosarcoma oncogene homolog F } \\ \text { ActD } & \text { actinomycin D } \\ \text { AzC } & \text { 5-aza-2'-deoxycytidine } \\ \text { SAHA } & N \text {-hydroxy- } N^{\prime} \text {-phenyloctanediamide }\end{array}$

\section{References}

1. Zhang, L.; Wang, J.; Liu, L.; Zheng, C.; Wang, Y. Synthesis and Antiproliferative Activity of Novel All-Trans-Retinoic Acid-Podophyllotoxin Conjugate towards Human Gastric Cancer Cells. Molecules 2017, 22, 628. [CrossRef] [PubMed]

2. Li, N.; Lu, Y.; Li, D.; Zheng, X.; Lian, J.; Li, S.; Cui, H.; Zhang, L.; Sang, L.; Wang, Y.; et al. All-trans retinoic acid suppresses the angiopoietin-Tie2 pathway and inhibits angiogenesis and metastasis in esophageal squamous cell carcinoma. PLoS ONE 2017, 12, e0174555. [CrossRef] [PubMed]

3. Liu, H.; Chen, F.; Zhang, L.; Zhou, Q.; Gui, S.; Wang, Y. A novel all-trans retinoic acid derivative 4-amino-2-trifluoromethyl-phenyl retinate inhibits the proliferation of human hepatocellular carcinoma HepG2 cells by inducing G0/G1 cell cycle arrest and apoptosis via upregulation of p53 and ASPP1 and downregulation of iASPP. Oncol. Rep. 2016, 36, 333-341. [CrossRef] [PubMed]

4. Orendas, P.; Kubatka, P.; Kajo, K.; Stollarova, N.; Kassayova, M.; Bojkova, B.; Pec, M.; Nosal, V.; Kiskova, T.; Zihlavnikova, K.; et al. Melatonin enhanced bexarotene efficacy in experimental mammary carcinogenesis. Neoplasma 2012, 59, 469-474. [CrossRef] [PubMed]

5. Ahlersová, E.; Ahlers, I.; Kubatka, P.; Bojková, B.; Môciková, K.; Gajdosová, S.; Onderková, H.M. Melatonin and retinyl acetate as chemopreventives in DMBA-induced mammary carcinogenesis in female Sprague-Dawley rats. Folia. Biol. (Praha) 2000, 46, 69-72. [PubMed]

6. Hörlein, A.J.; Näär, A.M.; Heinzel, T.; Torchia, J.; Gloss, B.; Kurokawa, R.; Ryan, A.; Kamei, Y.; Söderström, M.; Glass, C.K.; et al. Ligand-independent repression by the thyroid hormone receptor mediated by a nuclear receptor co-repressor. Nature 1995, 377, 397-404. [CrossRef] [PubMed]

7. Seol, W.; Choi, H.S.; Moore, D.D. An orphan nuclear hormone receptor that lacks a DNA binding domain and heterodimerizes with other receptors. Science 1996, 272, 1336-1339. [CrossRef] [PubMed]

8. Suzuki, Y.; Shimada, J.; Shudo, K.; Matsumura, M.; Crippa, M.P.; Kojima, S. Physical interaction between retinoic acid receptor and Sp1: mechanism for induction of urokinase by retinoic acid. Blood 1999, 93, 4264-4276. [PubMed]

9. Busson, M.; Carazo, A.; Seyer, P.; Grandemange, S.; Casas, F.; Pessemesse, L.; Rouault, J.P.; Wrutniak-Cabello, C.; Cabello, G. Coactivation of nuclear receptors and myogenic factors induces the major BTG1 influence on muscle differentiation. Oncogene 2005, 24, 1698-1710. [CrossRef] [PubMed]

10. Zusi, F.C.; Lorenzi, M.V.; Vivat-Hannah, V. Selective retinoids and rexinoids in cancer therapy and chemoprevention. Drug Discov. Today 2002, 7, 1165-1174. [CrossRef]

11. Sprecher, C.A.; Kisiel, W.; Mathewes, S.; Foster, D.C. Molecular cloning, expression, and partial characterization of a second human tissue-factor-pathway inhibitor. Proc. Natl. Acad. Sci. USA 1994, 91, 3353-3357. [CrossRef] [PubMed]

12. Petersen, L.C.; Sprecher, C.A.; Foster, D.C.; Blumberg, H.; Hamamoto, T.; Kisiel, W. Inhibitory properties of a novel human Kunitz-type protease inhibitor homologous to tissue factor pathway inhibitor. Biochemistry 1996, 35, 266-272. [CrossRef] [PubMed]

13. Rao, C.N.; Mohanam, S.; Puppala, A.; Rao, J.S. Regulation of ProMMP-1 and ProMMP-3 activation by tissue factor pathway inhibitor-2/matrix-associated serine protease inhibitor. Biochem. Biophys. Res. Commun. 1999, 255, 94-98. [CrossRef] [PubMed] 
14. Izumi, H.; Takahashi, C.; Oh, J.; Noda, M. Tissue factor pathway inhibitor-2 suppresses the production of active matrix metalloproteinase- 2 and is down-regulated in cells harboring activated ras oncogenes. FEBS Lett. 2000, 481, 31-36. [CrossRef]

15. Sato, N.; Parker, A.R.; Fukushima, N.; Miyagi, Y.; Iacobuzio-Donahue, C.A.; Eshleman, J.R.; Goggins, M. Epigenetic inactivation of TFPI-2 as a common mechanism associated with growth and invasion of pancreatic ductal adenocarcinoma. Oncogene 2005, 24, 850-858. [CrossRef] [PubMed]

16. Wong, C.M.; Ng, Y.L.; Lee, J.M.; Wong, C.C.; Cheung, O.F.; Chan, C.Y.; Tung, E.K.; Ching, Y.P.; Ng, I.O. Tissue factor pathway inhibitor-2 as a frequently silenced tumor suppressor gene in hepatocellular carcinoma. Hepatology 2007, 45, 1129-1138. [CrossRef] [PubMed]

17. Meex, S.J.; Andreo, U.; Sparks, J.D.; Fisher, E.A. Huh-7 or HepG2 cells: which is the better model for studying human apolipoprotein-B100 assembly and secretion? J. Lipid Res. 2011, 52, 152-158. [CrossRef] [PubMed]

18. ENCODE Project Consortium. An integrated encyclopedia of DNA elements in the human genome. Nature 2012, 489, 57-74. [CrossRef]

19. Moutier, E.; Ye, T.; Choukrallah, M.A.; Urban, S.; Osz, J.; Chatagnon, A.; Delacroix, L.; Langer, D.; Rochel, N.; Moras, D.; et al. Retinoic acid receptors recognize the mouse genome through binding elements with diverse spacing and topology. J. Biol. Chem. 2012, 287, 26328-26341. [CrossRef] [PubMed]

20. Portales-Casamar, E.; Arenillas, D.; Lim, J.; Swanson, M.I.; Jiang, S.; McCallum, A.; Kirov, S.; Wasserman, W.W. The PAZAR database of gene regulatory information coupled to the ORCA toolkit for the study of regulatory sequences. Nucleic Acids Res. 2007, 37, D54-D60. [CrossRef] [PubMed]

21. The Cancer Genome Atlas Research Network. Available online: http://cancergenome.nih.gov/ (accessed on 14 December 2016).

22. Tsuchiya, H. Kaplan-Meier Analyses of RAR $\alpha$ and RAR $\beta$ in HCC Patients; Tottori University: Tottori, Japan, 2018.

23. Eychène, A.; Rocques, N.; Pouponnot, C. A new MAFia in cancer. Nat. Rev. Cancer 2008, 8, 683-693. [CrossRef] [PubMed]

24. Igarashi, K.; Itoh, K.; Motohashi, H.; Hayashi, N.; Matuzaki, Y.; Nakauchi, H.; Nishizawa, M.; Yamamoto, M. Activity and expression of murine small Maf family protein MafK. J. Biol. Chem. 1995, 270, 7615-7624. [CrossRef] [PubMed]

25. De Aguiar Vallim, T.Q.; Tarling, E.J.; Ahn, H.; Hagey, L.R.; Romanoski, C.E.; Lee, R.G.; Graham, M.J.; Motohashi, H.; Yamamoto, M.; Edwards, P.A. MAFG is a transcriptional repressor of bile acid synthesis and metabolism. Cell Metab. 2015, 21, 298-310. [CrossRef] [PubMed]

26. Yamazaki, H.; Katsuoka, F.; Motohashi, H.; Engel, J.D.; Yamamoto, M. Embryonic lethality and fetal liver apoptosis in mice lacking all three small Maf proteins. Mol. Cell. Biol. 2012, 32, 808-816. [CrossRef] [PubMed]

27. Sieweke, M.H.; Tekotte, H.; Frampton, J.; Graf, T. MafB is an interaction partner and repressor of Ets-1 that inhibits erythroid differentiation. Cell 1996, 85, 49-60. [CrossRef]

28. He, K.H.; Juhl, K.; Karadimos, M.; El Khattabi, I.; Fitzpatrick, C.; Bonner-Weir, S.; Sharma, A. Differentiation of pancreatic endocrine progenitors reversibly blocked by premature induction of MafA. Dev. Biol. 2014, 385, 2-12. [CrossRef] [PubMed]

29. Moriguchi, T.; Hamada, M.; Morito, N.; Terunuma, T.; Hasegawa, K.; Zhang, C.; Yokomizo, T.; Esaki, R.; Kuroda, E.; Yoh, K.; et al. MafB is essential for renal development and F4/80 expression in macrophages. Mol. Cell. Biol. 2006, 26, 5715-5727. [CrossRef] [PubMed]

30. Kakehashi, A.; Kato, A.; Ishii, N.; Wei, M.; Morimura, K.; Fukushima, S.; Wanibuchi, H. Valerian inhibits rat hepatocarcinogenesis by activating $\mathrm{GABA}_{\mathrm{A}}$ receptor-mediated signaling. PLoS ONE 2014, 9, e113610. [CrossRef] [PubMed]

31. Vicente-Dueñas, C.; González-Herrero, I.; García Cenador, M.B.; García Criado, F.J.; Sánchez-García, I. Loss of p53 exacerbates multiple myeloma phenotype by facilitating the reprogramming of hematopoietic stem/progenitor cells to malignant plasma cells by MafB. Cell Cycle 2012, 11, 3896-3900. [CrossRef] [PubMed]

32. Nishizawa, M.; Kataoka, K.; Vogt, P.K. MafA has strong cell transforming ability but is a weak transactivator. Oncogene 2003, 22, 7882-7890. [CrossRef] [PubMed]

33. Pouponnot, C.; Sii-Felice, K.; Hmitou, I.; Rocques, N.; Lecoin, L.; Druillennec, S.; Felder-Schmittbuhl, M.P.; Eychène, A. Cell context reveals a dual role for Maf in oncogenesis. Oncogene 2006, 25, 1299-1310. [CrossRef] [PubMed]

34. Kelly, L.M.; Englmeier, U.; Lafon, I.; Sieweke, M.H.; Graf, T. MafB is an inducer of monocytic differentiation. EMBO J. 2000, 19, 1987-1997. [CrossRef] [PubMed] 
35. Watson, J.E.; Doggett, N.A.; Albertson, D.; Andaya, A.; Chinnaiyan, A.; van Dekken, H.; Ginzinger, D.; Haqq, C.; James, K.; Kamkar, S.; et al. Integration of high-resolution array comparative genomic hybridization analysis of chromosome 16q with expression array data refines common regions of loss at 16q23-qter and identifies underlying candidate tumor suppressor genes in prostate cancer. Oncogene 2004, 23, 3487-3494. [CrossRef] [PubMed]

36. Neaud, V.; Duplantier, J.G.; Mazzocco, C.; Kisiel, W.; Rosenbaum, J. Thrombin up-regulates tissue factor pathway inhibitor-2 synthesis through a cyclooxygenase-2-dependent, epidermal growth factor receptor-independent mechanism. J. Biol. Chem. 2004, 279, 5200-5206. [CrossRef] [PubMed]

37. Guo, H.; Lin, Y.; Zhang, H.; Liu, J.; Zhang, N.; Li, Y.; Kong, D.; Tang, Q.; Ma, D. Tissue factor pathway inhibitor-2 was repressed by CPG hypermethylation through inhibition of KLF6 binding in highly invasive breast cancer cells. BMC Mol. Biol. 2007, 8, 110. [CrossRef] [PubMed]

38. Lai, Y.H.; He, R.Y.; Chou, J.L.; Chan, M.W.; Li, Y.F.; Tai, C.K. Promoter hypermethylation and silencing of tissue factor pathway inhibitor-2 in oral squamous cell carcinoma. J. Transl. Med. 2014, 12, 237. [CrossRef] [PubMed]

39. Yuan, J.M.; Gao, Y.T.; Ong, C.N.; Ross, R.K.; Yu, M.C. Prediagnostic level of serum retinol in relation to reduced risk of hepatocellular carcinoma. J. Natl. Cancer Inst. 2006, 98, 482-490. [CrossRef] [PubMed]

40. Ashla, A.A.; Hoshikawa, Y.; Tsuchiya, H.; Hashiguchi, K.; Enjoji, M.; Nakamuta, M.; Taketomi, A.; Maehara, Y.; Shomori, K.; Kurimasa, A.; et al. Genetic analysis of expression profile involved in retinoid metabolism in non-alcoholic fatty liver disease. Hepatol. Res. 2010, 40, 594-604. [CrossRef] [PubMed]

41. Okita, K.; Izumi, N.; Ikeda, K.; Osaki, Y.; Numata, K.; Ikeda, M.; Kokudo, N.; Imanaka, K.; Nishiguchi, S.; Kondo, S.; et al. Survey of survival among patients with hepatitis $\mathrm{C}$ virus-related hepatocellular carcinoma treated with peretinoin, an acyclic retinoid, after the completion of a randomized, placebo-controlled trial. J. Gastroenterol. 2015, 50, 667-674. [CrossRef] [PubMed]

42. Tanaka, S.; Suto, A.; Iwamoto, T.; Kashiwakuma, D.; Kagami, S.; Suzuki, K.; Takatori, H.; Tamachi, T.; Hirose, K.; Onodera, A.; et al. Sox5 and c-Maf cooperatively induce Th17 cell differentiation via ROR $\gamma \mathrm{t}$ induction as downstream targets of Stat3. J. Exp. Med. 2014, 211, 1857-1874. [CrossRef] [PubMed]

43. Kajihara, M.; Sone, H.; Amemiya, M.; Katoh, Y.; Isogai, M.; Shimano, H.; Yamada, N.; Takahashi, S. Mouse MafA, homologue of zebrafish somite Maf 1, contributes to the specific transcriptional activity through the insulin promoter. Biochem. Biophys. Res. Commun. 2003, 312, 831-842. [CrossRef] [PubMed]

44. Hamada, M.; Nakamura, M.; Tran, M.T.; Moriguchi, T.; Hong, C.; Ohsumi, T.; Dinh, T.T.; Kusakabe, M.; Hattori, M.; Katsumata, T.; et al. MafB promotes atherosclerosis by inhibiting foam-cell apoptosis. Nat. Commun. 2014, 5, 3147. [CrossRef] [PubMed]

(C) 2018 by the authors. Licensee MDPI, Basel, Switzerland. This article is an open access article distributed under the terms and conditions of the Creative Commons Attribution (CC BY) license (http:/ / creativecommons.org/licenses/by/4.0/). 